\title{
Developing psychogeriatric services in Hong Kong
}

\author{
A. H. T. Pang, L. C. W. Lam and H. F. K. Chiu
}

Hong Kong is an international trade and finance centre situated on the southern coast of China, offering a unique blend of Western culture and Chinese tradition. With a largely private primary health care system, psychiatric services here have been predominately hospital centred. Following the 1992 Government Review of Rehabilitation Program Plan (Secretary of Health and Welfare, Hong Kong, 1992) development of community-based services has become the major local issue. Psychogeriatrics is the first sub-speciality to have achieved major progress in this area. Such a development illustrates how local psychiatrists faced the challenge of applying Western models to suit an Oriental population with a different socio-cultural value system.

\section{Historical aspects}

Traditionally, psychiatric patients over 60 were the responsibility of general adult psychiatrists. Two hundred long-stay beds in two wards were available in Kwai Chung Hospital (mental hospital) and Kowloon Hospital (general convalescent hospital) to provide institutionalised care for demented and chronic psychotic patients. In 1983, St James Settlement, a community centre jointly run by voluntary agency and the academic psychiatry department of the University of Hong Kong, was set up to provide weekly outpatient psychogeriatric assessments. No other specialised provision was available until the '90s.

Following the joint report Care of Elderly People With Mental Illness by the Royal College of Physicians of London and the Royal College of Psychiatrists (1989), the first fully specialised psychogeriatric unit was set up in the Chinese University of Hong Kong. With the publication of the Green Paper on Rehabilitation, the Hong Kong Government allocated new resources for the development

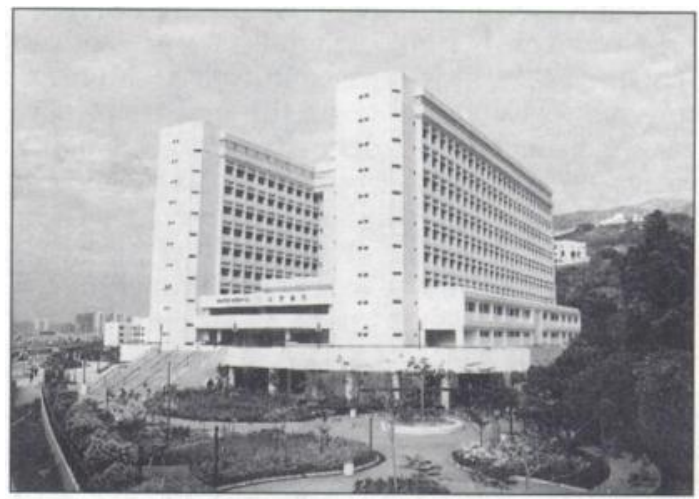

Shatin Hospital where the 20 beds assessment unit, 30 beds long-stay unit, and the outreach team is based.

of medical services to the elderly. This was followed by the creation of three more consultant-led teams in the last three years serving different regions of the colony. Being

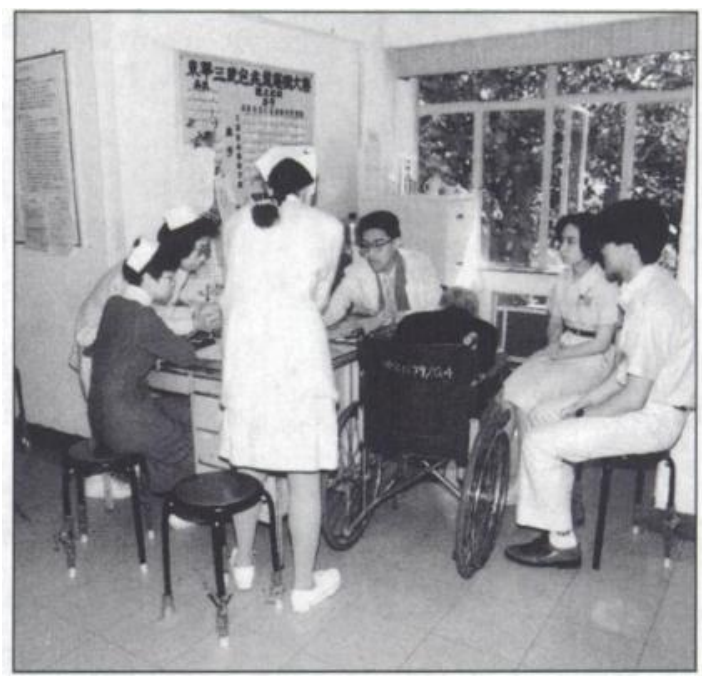

Consultation at the Old Age Home. 
the first and probably the most comprehensive, we describe the Chinese University psychogeriatric unit as an example of the type of services being developed locally.

The Chinese University Psychogeriatric Unit is headed by a senior lecturer, with a lecturer/ senior medical officer (post-MRCPsych trainee) and two medical officers (pre-MRCPsych trainees). They are supported by a team of specialised nurses, occupational therapists, physiotherapists, and social workers. They provide services for the New Territories East region with a total population of 750000 (Census and Statistics Department, Hong Kong, 1991). A multidisciplinary approach is adopted with an emphasis on continuity of care. Their services comprise the following.

\section{Hospital-based services}

In-patient facilities include an acute assessment unit (six beds) at the Prince of Wales Hospital. A sub-acute/convalescent (20 beds) and a long-stay (30 beds) unit are situated at Shatin Hospital. A specialised out-patient clinic with liaison services is provided for the two hospitals. Referrals come mainly from homes for the elderly, government clinics, private general practitioners, casualty department and ward liaisons. Patients are admitted to the assessment unit for observation, investigations and acute management. They would be discharged or transferred to the convalescent unit for further rehabilitation as appropriate.

\section{Community-based services}

The catchment area consists of a mixture of old villages and new satellite towns with a population of 65000 over 65 . This far exceeds the recommendations put forward in the joint report (Royal College of Physicians of London and the Royal College of Psychiatrists, 1989). To optimise resources, the community outreach programme concentrates on providing services to all 20 government registered homes for the elderly and five daycare centres within the area. Psychiatrists pay monthly visits to assess and follow-up patients. A survey carried out at 11 homes for the elderly after six months showed a decrease in out-patients and accident and emergency attendance with accompanying reduction in travel time for patients and escorts. Carers' satisfaction ratings were high, mainly on improved communication between medical and hostel staff, increased morale and better knowledge on management of elderly psychiatric patients. There was a slight increase in hospital admissions, probably due to increased awareness of psychiatric problems.

\section{Education and training}

Being a teaching hospital, the unit provides basic training for medical students and recognised membership training for medical officers. There is also an active in-service training programme with multidisciplinary articipation from all involved health professionals. With the shift of emphasis in psychiatric care to the community, public education is also an important accompaniment to the service. Besides giving public lectures and informal talks at community centres, the unit organises a half yearly course for the staff of homes for the elderly on the management of psychiatric problems in the elderly.

\section{Planning and development}

A psychogeriatric day hospital with transport provided for patients is due in 1995. This fills the gap within the service in providing a smooth transition from hospital to community. The community team will expand to include $a$ nurse and an occupational therapist. It is hoped that a multidisciplinary approach can be adopted within the outreach service.

Major difficulties in Hong Kong are the lack of social welfare provisions (Chiu, 1994). For instance, there are an estimated 9000 awaiting placement in homes for the elderly and a further 5500 infirmary placement (average waiting time is two to three years). With limited manpower and resources, comprehensive psychiatric care for the elderly will continue to be a challenge for local psychiatrists. As Hong Kong faces her momentous political change in 1997, and community psychiatry in China is in its early stages, this successful example of developing a service based on a modified Western model could offer important information for Chinese policy makers.

\section{References}

Census And Statistics Department. Hong Kong (1991) Hong Kong 1991 population census. Hong Kong:Government Printer. 
CHIU, H. (1994) Development of psychogeriatric services in Hong Kong. International Psychogeriatric Association Bulletin, 11, 18

Royal College OF PHYSicians OF LONDON AND ROYal COLLEGE OF PSYCHIATRISTS (1989) Care of Elderly People with Mental Illness.

Secretary Of Health AND Welfare, Hong Kong (1992) Green Paper on equal opportunity and full participation. Better Tomorrow for All. Hong Kong: Government Printer.
*A. H. T. Pang, Lecturer, Department of Psychiatry, 11th Floor, Prince of Wales Hospital, Shatin, NT, Hong Kong; L. C. W. Lam, Lecturer, and H. F. K. Chiu, Senior Lecturer, Department of Psychiatry. Chinese University of Hong Kong

*Correspondence

\title{
Management for Psychiatrists
}

\author{
Second Edition \\ Edited by Dinesh Bhugra and Alistair Burns
}

Since the last edition rapid changes in the NHS have meant that clinicians have had even less time to manage change and keep up to date with health reforms. For this new edition, all the existing material has been extensively revised. In addition, eight new chapters have been added, including a section on changes and conflicts covering large areas of potential difficulty that clinicians may have to deal with.

As before, the emphasis is on how to get the best for and from services. Practical advice is given on management. Negotiation techniques and time and stress management are also covered.

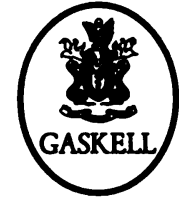

\section{$£ 20.00 \bullet 360$ pp. $\bullet 1995 \bullet$ ISBN 0902241850}

Available from bookshops and from the Publications Department, Royal College of Psychiatrists, 17 Belgrave Square, London SW1X 8PG (Tel. 0171-235 2351 extension 146) 